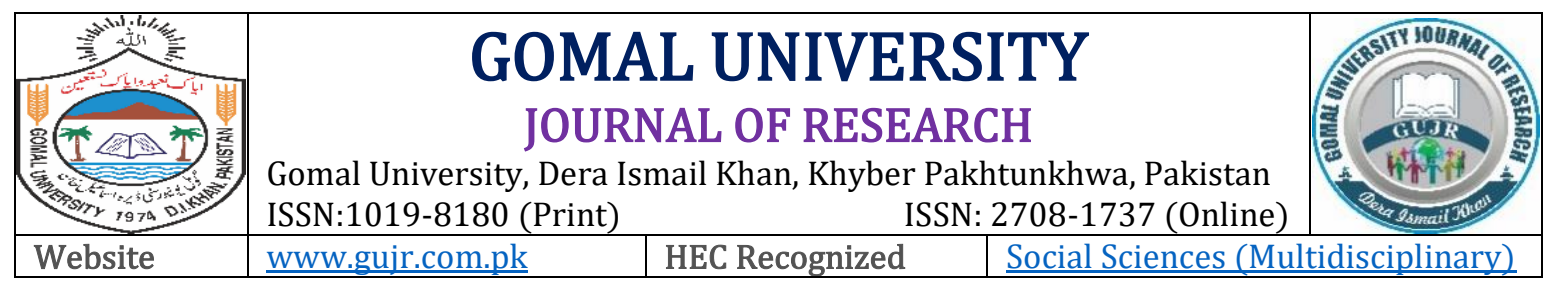

\title{
CURRICULUM CHANGE IN PAKISTAN: LESSONS LEARNED FROM THE PAST AND THE WAY FORWARD
}

\author{
Muqaddas Butt' ${ }^{1}$, Shumaila Mahmood ${ }^{2} \&$ Tanzeela Urooj $^{3}$ \\ ${ }^{1}$ Assistant Professor, Department of Education, University of Education, Lahore, Pakistan \\ ${ }^{2}$ Assistant Professor, Department of Education, University of Education, Lahore, Pakistan \\ ${ }^{3}$ Assistant Professor, Department of Education, University of Loralai, Balochistan, Pakistan
}

\begin{tabular}{|c|c|}
\hline ARTICLE INFO & RACT \\
\hline $\begin{array}{l}\text { Keywords: } \\
\text { English Curriculum, } \\
\text { Curriculum Change, } \\
\text { Curriculum Change, } \\
\text { Teachers' Involvement in } \\
\text { Change }\end{array}$ & \multirow{2}{*}{ 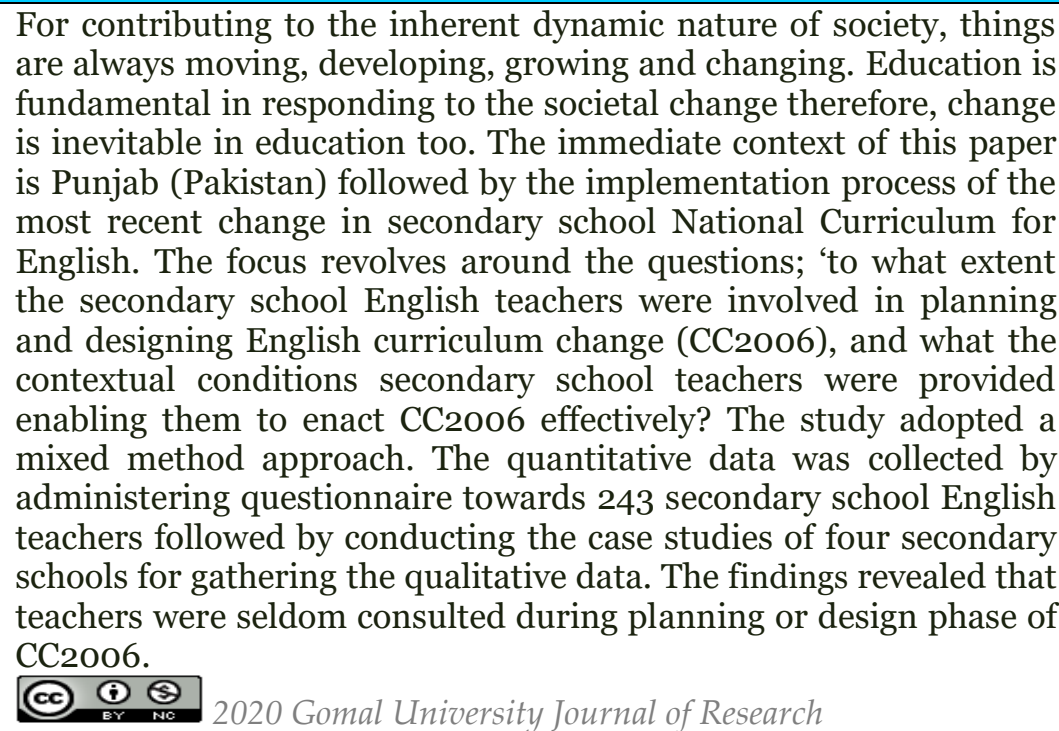 } \\
\hline $\begin{array}{l}\text { Article History: } \\
\text { Date of Submission: } \\
\text { 20-09-2020 } \\
\text { Date of Acceptance: } \\
\text { 19-03-2021 } \\
\text { Date of Publication: } \\
\text { 31-03-2021 }\end{array}$ & \\
\hline Corresponding Author & Shumaila Mahmood: shumaila.mahmood@ue.edu.pk \\
\hline $\mathrm{DOI}$ & https://doi.org/10.51380/gu \\
\hline
\end{tabular}

\section{INTRODUCTION}

Curriculum change 2006 termed as CC2006 in this paper is the phenomenon that most recently appeared on educational landscape of Pakistan and its implementation was asserted as biggest challenge of educational reform in Pakistan (Aziz, Bloom, Humair, Jimenez, Rosenberg \& Sathar, 2014). The stage for CC2O06 was set in August 2004 when newly elected government of Pakistan decided to introduce education reform in the country. The education reform process included the announcement of new National Education Policy, National Education Census and changing the curricula (Ministry of Education, 2009). In reality, change in secondary school curriculum was initiated in 2006 and as result, scheme of studies for classes I to XII was reviewed and curriculum of 25 compulsory subjects (include Secondary English curriculum) were changed (Majeed, 2009). 
The Provincial Textbook Boards were instructed by the Federal Ministry of Education to prepare quality textbooks in collaboration with the private sector publishers before the commencement of the new academic session in August 2007. Figure 1 presents the overview of time frame set out for CC2006 related tasks. Research suggests that developing a new curriculum requires the input of different stakeholders like policy makers, teachers, school heads, parents, community members, students, the district administrators, public health practitioners and the school boards (Dillon, 2009).

The role of teachers as stakeholders is of the immense importance as their insights are critical for the underpinning intervention feasibility, acceptability and performance (Middleton, Geoff, Evans, Adam, Keegan, Richard, Bishop, Daniel, Evans and Donna, 2014). Thus, the central tenant of this study was to investigate whether and to what extent the secondary school English teachers were involved (if they) in process of English CC2006 and what working context, conditions and support were available to teachers to facilitate implementation of English CC2006. Although, the research on curriculum changes 2006 (CC2006) in Pakistan and its implementation gained great interest in academic circles, however a review of related literature shows that most studies revolve around the issues such as the imperative for education system reform in Pakistan (Jamil, 2009; Aziz et al., 2014) and/or the process and scope of the reforms (Barber, 2013; Aziz et al., 2014). Thus, it deemed timely and worthwhile to conduct a study on the curriculum change 2006 (CC2006) with particular focus on exploring English teachers' perceptions of the most recent curriculum change in Pakistan and examining the contextual conditions within which the teachers were supposed to enact change. Choosing English curriculum change as the focus for present research had several reasons.

English has become an essential tool for international communication, necessary for technological advancement (Kennedy, 1996, McFarland, 2008) and plays central role in educational curriculum of many developing countries (Sheehan, 2013). The rapid process of the globalization has further strengthened dominance of English (Barrot, 2018). Secondly, the National educational policies of Pakistan place English language teaching and learning as priority agendas. This priority is much evident through the National Professional Standards for Teachers that place great emphasis on teaching of English as foreign/second language (Ministry of Education, 2009). Therefore, quality of English language teaching has always been a point of great concern in Pakistan. This model is adaptation of Biesta and Tedder' (2007) ecological perspective of teacher agency. Through this model, we have tried to establish an orderly connection amid conceptual and contextual aspects of curriculum change as teachers' involvement has potential effect on curriculum change in number of ways. The model also indicates that before introducing curriculum change, a contextual scan is crucial. Without understanding or upgrading ecological conditions including existing practices, organizational structure, culture and resources, change may be both the difficult and potentially insignificant.

\section{LITERATURE REVIEW}

Curriculum change is the constant process (Cheng, 1994), which is complex and problematic at the same time (Fullan, 1993; Reid \& Walker, 2012, Miles, 2020). New initiatives, procedures and systems work well when the participation of and ownership of the teachers who are responsible to implement them is considered (Guskey, 1995; Spillane, 1999; Smit, 2005). Teachers' contribution to and participation in change process is vital and no change can actually happen without their understanding and participation (Kirk \& MacDonald, 2001; Wang, 2007). However, it has been noted that the powerful institutional forces that exist in the most education systems delimit the possibilities for teachers to be agents within the re-contextualizing field (policymaking, textbooks/ syllabus writing). The marginalising teachers in this process prohibits them to make sense of, and 
operationalize the ideas advanced by the reformers and other top authorities (Kirk \& MacDonald, 2001).

\section{Teachers' Involvement in Curriculum Change Process}

The existing research studies (Fullan \& Hargreaves, 1992; Tabulawa, 1998; Utomo, 2005; Shkedi, 2006; Shawer, 2010; Sinnema, Nieveen \& Priestley, 2020) concur that reform will not be effective without ownership by teachers and education leaders. Without a sense of the ownership, teachers may be unhappy and resist curriculum change (Wang, 2007; Marton, 2006 cited in Dello, 2009). Teachers' reaction to change is determined by change approach (top down, bottom-up) employed. Teachers are more likely to exhibit reactive or passive agency if change is directed from the top (Jenkins, 2014). Alwan (2005) investigation into teachers' participation in new English language curriculum in United Arab Emirates revealed teachers' marginal and passive role throughout the curriculum change process. Similarly, incongruous practices and procedures have been reported about curriculum change in Pakistan. Memon (1989) argued that curriculum changes in Pakistan had been subsequent of rigid and 'one-way mechanism' which assumes that teachers are 'humble servants' of system, who have to comply with instructions and consequently to them show little or no enthusiasm about the introduced. A mismatch between teachers' teaching styles and students' desired learning outcomes may be evident. Moreover, ambiguities of curriculum change give rise to teachers' concerns during its implementation. It is evident that if curriculum initiators ignore teachers in curriculum change process, change may not as effective intended (Wallace \& Priestley, 2011).

Several large-scale reforms failed because they were introduced hastily without involving teachers and enabling them to prepare to implement the reforms (Spillane, 2002 cited in Utomo, 2005). Therefore, a significant amount of empirical literature points out that, if sound implementation of curriculum is desired, ownership sense is needed to provoked in teachers and other prospective users. The involvement of practising teachers may generate more realistic and relevant reform projects (Kirk \& MacDonald, 2001). Thus, involving teachers in conceptual and development stages of curriculum change can increase their professional competence and understanding of innovation in question and subsequently, develop their commitment to implement change (Franke et al., 1998; Flores, 2005; Rahman, 2014). Enlightening teachers about focus and content of curriculum change helps them identifying their teaching priorities and modify these priorities for learners' development in English (Rahman, 2014) and essential knowledge (Cross et al., 2002). Teachers are more likely to change their conventional practices if their voices are heard and valued during the curriculum change process (Knight, 2009; Sinnema, et al., 2020). Wallace and Priestley (2011) indicated effectiveness of a bottom-up approach to empower teachers to create their own reform methods to implement new curricula. Resistance can be reduced if teachers own the project and if there is appropriate support at all levels of system (Galton, MacBeath, \& Steward, 2002; Mutch, 2012).

\section{Change Implementation and Contextual Support}

Besides teachers' involvement in the change process, contextual scan of the reform context like identifying the compatibility of and improving the structure, culture and conditions of the schools where change needs to be implemented is equally important. A decline in ability to bridge the gap of policy ideas and contextual realities of classrooms has become frustrating problem. Hendricks (2008) appeared to argue that reforms related policies very often ignore the specific contexts in which these are intended to be implemented. Cohen and Hill (2001) seem agree to Hendricks when they write: Effective implementation of policies depends not only on making the connections among often disparate agencies, but also on creating adequate opportunities for professionals to learn what the policy requires of them (p. 9). Gap between policy and practice is not a new debate 
in the literature of education reforms. As, educational policies communicate official expectations pertaining to the roles of teachers towards new curriculum (Hendricks, 2008) thus, policy itself is regarded as one of the hardest nuts to crack (Darling, 1998, Apple, 2018). Gap between policy or rationale underlying change and execution process of change gives rise to several challenges (Pree, 2012; Drew, Priestley \& Michael, 2016). Gibson and Brooks (2012) advised that decisions about what new experiences curriculum should provide and how and when to provide, need to be made rationally.

In a study of the impact of change on primary school teachers working conditions, most of the teachers rated insufficient time as top problem (Galton et al., 2002). Consistent to this finding, the researchers (Fernandez, Sushama, Ritchie \& Garth, 2003; Gibson \& Brooks, 2012; Coughlan, 2013) have also indicated the lack of time as a recurrent theme and concluded that teachers were expected to implement too much content with the insufficient time. Similarly, many teachers in South Africa reported that the revised national curriculum (2005) overloaded their school work (Bantwini, 2009) and considered the timetable devised for implementing the changes absolutely unrealistic (Coughlan, 2013). Why teachers do not embrace pedagogical change with the change in curriculum is an ongoing debate in literature. It has been noted that the top-down models of curriculum reform developed outside the school and then transmitted to teachers (Fullan, 1972; Grossman, Onkol and Sands, 2007) brings little or no improvement in the classrooms' practices (Cuban, 2013). Coercing teachers to implement curriculum change without providing them time to understand the changes gives rise to stress. It is evident from school improvement literature that without organisational change pedagogical improvement is merely a day dream (Harris, 2003; Sinnema et al., 2020), because change in school structure, culture and work conditions, which are weighty to what teachers experience in school routine are hardly ever reformed (Barrot, 2018).

Teachers may find new pedagogical ideas unsuitable to their context or their students (Fernandez et al., 2003; Hord, et al., 1987 in Plessis \& Erika, 2005). The practices that successfully influence teachers' commitment are difficult to attain unless corresponding changes are made in the school leadership, school structure and critically, conditions of classroom (Ali, 2011; Cheung \& Wong, 2011). Because of the limited space, teachers were afraid to administer interactive activities such as group work/discussion. Lack of alignment between new curriculum and assessment systems is also one of reasons of failure of reforms (Altunoglu, 2012; Sinnema et al., 2020). Many English language teachers in China complained about the assessment system that was not elevated to assess students learning of new curriculum (Wang, 2007). Similarly, Pakistan went through the same motions of reform, without actually changing much in other aspects of school education. An incremental approach to change, in which one aspect (curriculum) is reformed while other vital components of teaching and learning, such as external examinations, remain untouched (Rowan, 1996 cited in Darling, 1997, Bantwini, 2009) could prevent schools and teachers from enacting new ideas (Priestley, 2011). Considering the change essentials, South African Curriculum Review Committee (2005) recommended that the curriculum needs to be streamlined through aligning it with assessment strategies, improving teacher quality and providing support materials (Bantwini, 2009).

Teachers' professional development has been identified as one of the challenging prerequisites to raise teachers' quality for successful implementation of new curriculum (Harley \& Wedekind, 2004; Gibson \& Brooks, 2012; Priestley \& Drew, 2019). It is evident from the review of related literature that teachers' involvement in the reform process is essential and in order to establish a harmony with the demands of the new curriculum all aspects of schooling must be reviewed and upgraded. The last curriculum changes in Pakistan took place in 2006. In 2010, as a result of 18th 
amendment in the constitution, education has been relegated to the provinces. In the present times when the Pakistan Tehreek-i-Insaf government has announced to embark upon the Single National Curriculum (Kamran, 2020) the study of phenomenon of curriculum changes in 2006 seems crucial as it will not only reveal the extent to which teachers were involved in curriculum change process in the past but also unveils the contextual challenges and problems that caused poor implementation of CC2006. Thus, the lessons learnt from the past reforms could guide the development and implementation of Single National Curriculum. The findings of present research led us to recognize the fact that successful curriculum change is more likely to happen if realistic goals are set within desired context (Jones \& Anderson, 2001) and sufficient help and support is provided in change in particular context (Priestley \& Drew, 2019; Gleeson, Klenowski, \& Looney, 2020).

\section{METHODOLOGY}

This study adopted the mixed method approach. Firstly, the data were collected by a five-point Likert scale questionnaire to 243 secondary school English teachers where the respondents had to choose one option to indicate their level of agreement/disagreement on a scale of 1-5 (Strongly Disagree $=1$ to Strongly Agree=5). Secondly, in order to acquire a profound understanding of the research problem the researchers decided to conduct four case studies involving semi-structured interviews of eight teachers out of those 243 teachers who responded questionnaire and their head of schools. In that way, the conveniently drawn sample (case study) served as a subset of the probability drawn sample (questionnaires). In order to draw teachers' sample, random sampling techniques was employed. The convenient sampling technique was used to select the case study sample.

The questionnaire data was analysed using the frequency counts and descriptive statistics. All the interviews were audio recorded. Thus, in order to analyse the interview data, the audio tapes were transcribed and analysed by using NVivo version 10. Nevertheless, the process of transcribing the interview data was a prolonged and demanding task, but it produced the incredible results. The themes emerged from the interviews covered several sub-themes that are identified in the results section. The vertical analysis of the case study data was carried (Miles \& Huberman, 1994) which entailed a separate analysis of each case study school. The present research focuses on English curriculum change and professional development of the secondary school English teachers only. Therefore, the different results might have been produced if change in the curriculum of other subjects is studied. Similarly, it is assumed that a large survey sample may also lead to different findings.

\section{RESULTS OF STUDY}

The key results obtained through the methodological corroboration (questionnaire data and case studies) provided a rich manifestation of arguments posed in this research in order to reach the conclusion. The study comprises the quantitative and qualitative results as presented in current section.

\section{Quantitative Data Analysis}

The results attained through the quantitative data using descriptive analysis have been presented here however, qualitative results have also been presented to provide the accurate understanding about the research concept to produce the better results and to reach the conclusion of the study. The quantitative results through frequencies helps in describing concepts more accurately and comprehensively. 
Butt et al... Curriculum Change in Pakistan

Table 1

Curriculum Change is Effective When Well Planned

\begin{tabular}{lcccccc}
\hline & Frequency & Percent & Valid \% & Cumulative \% & Mean & SD \\
\hline Uncertain & 9 & 2.5 & 2.6 & 2.6 & & \\
Agree & 207 & 58.0 & 60.5 & 63.2 & 4.3421 & .5277 \\
Strongly Agree & 126 & 35.3 & 36.8 & 100.0 & & \\
\hline Total & 342 & 95.8 & 100.0 & & & \\
\hline
\end{tabular}

Table 2

No involvement in Curriculum Change

\begin{tabular}{lcccccc}
\hline & Frequency & Percent & Valid \% & Cumulative \% & Mean & SD \\
\hline Uncertain & 83 & 23.2 & 24.3 & 24.3 & & \\
Agree & 227 & 63.6 & 66.4 & 90.6 & 1.9444 & .7846 \\
Strongly Agree & 32 & 9.0 & 9.4 & 100.0 & & \\
\hline Total & 342 & 95.8 & 100.0 & & & \\
\hline
\end{tabular}

Table 3

Provided with Timely Information about Curriculum Change

\begin{tabular}{lcccccc}
\hline & Frequency & Percent & Valid \% & Cumulative \% & Mean & SD \\
\hline Strongly Disagree & 21 & 5.9 & 6.1 & 6.1 & & \\
Disagree & 218 & 61.1 & 63.7 & 69.9 & 2.3509 & 0.7579 \\
Uncertain & 65 & 18.2 & 19.0 & 88.9 & & \\
Agree & 38 & 10.6 & 11.1 & 100.0 & & \\
\hline Total & 342 & 95.8 & 100.0 & & & \\
\hline
\end{tabular}

Table 4

Provided Awareness about New Role Related to New Curriculum and Pedagogy

\begin{tabular}{lcccccc}
\hline & Frequency & Percent & Valid \% & Cumulative \% & Mean & SD \\
\hline Strongly Disagree & 192 & 53.8 & 56.1 & 75.4 & 3.9444 & .8963 \\
Disagree & 23 & 6.4 & 6.7 & 8.8 & & \\
Uncertain & 36 & 10.1 & 10.5 & 19.3 & & \\
Agree & 7 & 2.0 & 2.0 & 2.0 & & \\
Strongly agree & 84 & 23.5 & 24.6 & 100.0 & & \\
\hline Total & 342 & 95.8 & 100.0 & & & \\
\hline
\end{tabular}

Table 5

Provision of Required Resources by School to Teach New Curriculum

\begin{tabular}{lcccccc}
\hline & Frequency & Percent & Valid \% & Cumulative \% & Mean & SD \\
\hline Strongly Disagree & 74 & 20.7 & 21.6 & 21.6 & 2.2164 & 1.0188 \\
Disagree & 194 & 54.3 & 56.7 & 78.4 & & \\
Agree & 74 & 20.7 & 21.6 & 100.0 & & \\
\hline Total & 342 & 95.8 & 100.0 & & & \\
\hline
\end{tabular}


Table 6

New Curriculum Put Pressure on Me and My School

\begin{tabular}{lcccccc}
\hline & Frequency & Percent & Valid \% & Cumulative \% & Mean & SD \\
\hline Disagree & 17 & 4.8 & 5.0 & 5.0 & 4.0263 & .7199 \\
Uncertain & 33 & 9.2 & 9.6 & 14.6 & & \\
Agree & 216 & 60.5 & 63.2 & 77.8 & & \\
Strongly Agree & 76 & 21.3 & 22.2 & 100.0 & & \\
\hline Total & 342 & 95.8 & 100.0 & & & \\
\hline
\end{tabular}

Table 7

Provided Organized Professional Development \& Capacity Building Opportunities

\begin{tabular}{lcccccc}
\hline & Frequency & Percent & Valid \% & Cumulative \% & Mean & SD \\
\hline Strongly Disagree & 2 & .6 & .6 & .6 & 3.3743 & .9381 \\
Disagree & 236 & 66.1 & 69.0 & 100.0 & & \\
Agree & 104 & 29.1 & 30.4 & 31.0 & & \\
\hline Total & 342 & 95.8 & 100.0 & & & \\
\hline
\end{tabular}

Table 8

Allocation of Sufficient Funds to School for Teachers' Professional Development

\begin{tabular}{lcccccc}
\hline & Frequency & Percent & Valid \% & Cumulative \% & Mean & SD \\
\hline Strongly Disagree & 24 & 6.7 & 7.0 & 7.9 & 2.7164 & 1.0659 \\
Disagree & 161 & 45.1 & 47.1 & 55.0 & & \\
Uncertain & 38 & 10.6 & 11.1 & 66.1 & & \\
Agree & 111 & 31.1 & 32.5 & 98.5 & & \\
Strongly Agree & 5 & 1.4 & 1.5 & 100.0 & & \\
\hline Total & 342 & 95.8 & 100.0 & & & \\
\hline
\end{tabular}

Table 9

Curriculum Change and Meaningful Interactions Between Teachers and Administrators

\begin{tabular}{lcccccc}
\hline & Frequency & Percent & Valid \% & Cumulative \% & Mean & SD \\
\hline Disagree & 11 & 3.1 & 3.2 & 3.2 & 4.1637 & \\
Uncertain & 13 & 3.6 & 3.8 & 7.0 & & 0.6380 \\
Agree & 227 & 63.6 & 66.4 & 73.4 & & \\
Strongly Agree & 91 & 25.5 & 26.6 & 100.0 & & \\
\hline Total & 342 & 95.8 & 100.0 & & & \\
\hline
\end{tabular}

\section{Table 10}

Challenges and Difficulties Teachers Faced During Implementation of CC2OO6

\begin{tabular}{|c|c|c|c|c|c|c|}
\hline & Frequency & $\%$ & Valid \% & Cumulative $\%$ & Mean & SD \\
\hline $\begin{array}{l}\text { Students related challenges and } \\
\text { difficulties }\end{array}$ & 89 & 24.9 & 26.0 & 26.0 & 3.0058 & 1.5143 \\
\hline $\begin{array}{l}\text { Resources \& collegial culture } \\
\text { related }\end{array}$ & 82 & 23.0 & 24.0 & 100.0 & & \\
\hline $\begin{array}{l}\text { Curriculum related challenges } \\
\text { and difficulties }\end{array}$ & 73 & 20.4 & 21.3 & 59.4 & & \\
\hline Administration $\quad$ related & 57 & 16.0 & 16.7 & 76.0 & & \\
\hline
\end{tabular}


challenges and difficulties

Teachers' competencies related challenges \& difficulties

Total
41

342
11.5

12.0

38.0

\section{Qualitative Data Analysis}

The findings emerging from qualitative data analysis using thematic analysis regarding teachers' engagement in planning and designing of curriculum change 2006 and the presence of suitable context for them equipped with necessary resources and support to enact this change are given here. The qualitative data obtained through semi-structured interviews of the case study teachers was transcribed and translated, out of which certain patterns were developed. In order to build on these patterns, the codes were assigned to the qualitative data which therefore resulted into major themes. Based on the focus and subject matter of participants' narratives, the following themes emerged:

- Teachers' and Principals' general perceptions of the curriculum change about CC2006

- Teachers' involvement in the decision making of CC2006 in the concerned context

- Teachers' views on availability of appropriate context \& resources to implement CC2006

- Challenges \& difficulties teachers encountered about curriculum change implementation

Aforementioned themes and recurring patterns reflected case study participant teachers' patterns of belief regarding curriculum change 2006 and presence of apt ecology essential for its successful execution. Interestingly, description of one theme found referring to subject matter of another theme.

\section{Theme I: Teachers' and Principals' Perceptions of Curriculum Change CC20o6}

The participants expressed positive views about the CC2006 however; they revealed that CC2006 was a phenomenon introduced hastily without taking into account the practical implications of such a huge decision. Therefore, this is evident from the following statements given by concerned respondents:

Our Government has changed curriculum without proper planning actually, this is a bitter reality that the people who design curriculum content in Pakistan are completely unaware to the ground reality. They remain sitting in their offices and are unaware to the miserable condition of our schools and (understanding) level of our students. We are the teachers, we are in field; we have to face these constraints, (Teacher 1, school C). Curriculum has been changed without proper planning and arranging implementation apparatus (Teacher 1, school B)

\section{Theme II: Teachers' Involvement in Decision Making of CC2006}

With knowledge and experiences teachers are considered central to any curriculum reform effort but following excerpts show that teachers were not taken on board and deliberated in planning and design process of CC2006:

At any stage of curriculum change we had not been asked to share our opinion and thoughts (Teacher2, School C).

The following interview statement revealed that teachers remained uninvolved and uninformed in the decision making of CC2006. We came to know about CC2006 when the process of textbooks publication was almost completed (Teacher 2, school A). 
The top-down approach adopted to introduce English curriculum change (CC2006) was criticized by most of teachers. Teachers advocated a participatory approach of curriculum change. Another teacher echoed the same views:

Change is a part of education system, but, before the initiating change, teachers and head of schools must be consulted. Specially, the teachers should be provided with the training opportunities to prepare them for implementing change in their schools (Teacher 1, school B).

\section{Theme III: Teachers' views on Availability of Appropriate Context and Resources}

Regarding the provision of required resources to teach new curriculum, the case study teachers validate questionnaire response and pointed out the scarcity of resources they were experiencing:

Lack of teaching learning equipment is a big issue in our school (Teacher 2, School A). Other subjects may be taught without AV Aids, but so far as the teaching of language is concerned, it is not possible without the use of A V Aids (Teacher 2, school D)

No orientation provided to the teachers related to the CC2006 and absence of appropriate resources had put pressure on teachers and made it hard for them to enact it effectively. This is illustrated in the following quotations selected from interviews: New curriculum is so lengthy that it could not be covered within limited time by using inadequate resources (Teacher 2, school D).

When I started teaching new English curriculum to my 9th class students, I adopted 'direct method' but students' feedback was not encouraging. They showed very little interest and least involvement in the lessons.......to me, students' understanding and their involvement in the lesson is the most desired thing hence, I started teaching them through my old method (indirect method). Due to difficult lexis (of new curriculum) students don't acquire the lesson properly............ after a month they will have to appear in their final exam, so at this stage, I don't want to do experiment of teaching them through any other method (Teacher 2, school A).

Organized professional development \& capacity building opportunities that enhance teacher's knowledge and skills to perform the change implementation related tasks effectively, were either missing or untimely.

During my six-year teaching career I had been provided with only one professional development opportunity which I feel is insufficient (Teacher 2 school B).

One of the case study teachers held the school administration responsible for being unsupportive allowing them to attend any capacity building program:

Usually, the training programs are held during term time and the school administration does not want to send teachers on professional training during peak teaching time (Teacher 2, School C).

Further, the discontentment to the number and duration of professional development activities was also noted.

(however) expecting successful implementation of curriculum after providing just 10 to 15 days training is not a wisdom (Teacher 1 , school D). To be able to achieve the goals of curriculum change, first, we need to update and upgrade our teacher education curriculum. A few days training cannot instil necessary skills among teachers required for teaching the advanced level curriculum (Teacher 1 , school c) 


\section{Theme IV: Challenges to Teachers towards Curriculum Change Implementation}

Qualitative data analysis identified that challenge that teachers confronted during implementation of CC2006 largely fall into following five categories into following by teachers: Student-related challenges and difficulties, Resources-related challenges and difficulties, Curriculum-related challenges and difficulties, Administration-related \& and difficulties \& Teacher-related challenges and difficulties.

Most challenges and difficulties teachers faced during implementation of CC2006 were related to students.

We (the teachers) are struggling a lot to teach the new curriculum and if the teachers do not feel at ease, how the students could remain unaffected (Teacher 1, school A).

Results suggested that there were some challenges that were associated with teachers (12\%) or the new English curriculum (CC2006) itself (i.e., length of the curriculum, late provision of textbooks to schools/students etc.).

The curriculum change did not only disturb the teachers but also students. 2006 curriculum change has put extra burden on teachers and they got stunned after seeing the new textbooks comprising completely different stuff from that of last year curriculum. The exercises in new textbook are so lengthy to complete within given short time span in terms of content, new English curriculum is mainly linguistics oriented and teaching linguistic based curriculum to nonEnglish students by teacher holding general qualification is big challenge. Students in Pakistan take English language learning as a threat. Therefore, the upshot is that the teachers in the present situation are confused and so as the students (Teacher 1, school A).

One of the case study teachers showed serious concerns about the dimension of the new English curriculum (2006) in the following words:

(the) aim of teaching English either as subject; literature or language is also vague (Teacher 1, school B)

The findings of this research clearly highlight importance of teachers' active engagement in the curriculum change process. The findings also suggest that the deficits of CC2006 may be taken into consideration in times when the Punjab provincial government is preparing to introduce new curricula from early childhood to higher secondary level in 2019.

\section{Curriculum Change: A Way Forward}

Identifying the research gaps and drawing on findings of this study, the lack of a comprehensive model of the implementation of curriculum changes in the general and absence of a systematic framework for implementing Curriculum changes in coming years, a curriculum implementation framework model is proposed in this study to completely understand. Proposed cyclical model details necessary decisions and actions that an implementation process of curriculum change may entail. Instead of top-down style to curriculum change, proposed model promotes participatory approach emphasizing the engagement of, and communication between administrators, teachers, school head, teaching communities, professional association, academics \& parents, for successful implementation of curriculum change. It suggests that involvement of stakeholders in meaningful discussion around curriculum is vital for high-quality curriculum to embraced and implemented as intended. Teachers as the end users of curriculum are key stakeholders who should be engaged in all phases of change process (Pree, 2012). In a context like Punjab, geographical, political and economic conditions make it difficult to involve teachers in all decisions however, it is suggested 
that participation should be facilitated to ensure commitment to proposed curriculum change in future.

Framework strongly prioritises timely and explicit communication between curriculum reformers and practitioners (Virgilio, 1984; Köksal, 1995). Development phase in model entails developing curriculum resources such as textbooks and teacher guides agreed by the different stakeholders (educationists; subject specialists; principals; teachers; students \& parents). It strongly stresses integrating the component of teacher professional training and development with development phase of curriculum resources and teacher guides. The idea of integrating teacher development within that phase is based on previous research that consistently show that teachers' involvement in resource development and guides helps them to feel empowered in the institutions. It fosters teachers' professional competence through hands-on experiences. TPD should be structured and initiated in an integrated way with the launch of curriculum change. Based on the finding that secondary English teachers in Punjab were offered only one sporadic and centralized TPD activity for the implementation of CC2006, another independent model, the Inter-tier collaborative TPD support system (See Figure 4) is proposed. To make TPD a coherent and sustainable activity, this multi-site TPD model is closely linked with change implementation framework model and focuses on different forms of professional learning to implement in letters and spirit to attain and support which teachers could be offered at macro (province and district) or at micro (school/classroom) levels.

The professional support suggested at each level not only includes a range of off-site standardized development activities but also involves on-the-job learning activities like collaborative research, formal/informal dialogue and joint teacher meetings; elements that were found missing in this study. This is vital to mention that this model does not discard traditional large group workshops from the offering list of TPD. Rather the focus of workshops shifts from delivery mechanisms to the processes by which teachers can learn through mutual interaction and embedding new ideas in their practice. It reflects the notion that TPD is not a single event (Fullan \& Hargreaves, 1992) or a collection of random detached activities (Guskey, 2000) but an appropriate support system/ culture. Both models 7.1 and 7.2 promote idea of inter-tier collaboration (Ministry of Education, 2009) among province, district and schools. Extending the change context to school and local authority and establishing an active support system at each level through Inter-tier collaborative TPD support system could have manifold benefits. On one hand it could help the reform makers or TPD organizers to identify and learn about teachers' difficulties related to reforms (Bantwini, 2009) and on other hand, enable teachers to cope with potential challenges that may arise during the implementation of change. In addition, extending TPD opportunities to district and school level as the model suggests, could empower district administrators and heads of schools and actuate them to create more informed, deliberate and the high quality TPD for teachers (Sparks, 2002).

The model encourages reform makers and TPD facilitators to maintain close working relationship with teachers so that they can identify and learn about teacher difficulties relating to curriculum change (Bantwini, 2009). The Inter-tier collaborative TPD support system model also reinforces the idea that change in classroom practices is unlikely to be achieved if TPD is intermittent and detached from specific school and internal classroom practices. The curriculum implementation framework on other hand further highlights significance of coherent monitoring and evaluation mechanisms in the successful implementation of change. Monitoring not only helps to identify how teachers comprehend curriculum change and what challenges they confront in enacting this change, but also provides evidence of whether or not teachers enacted change as desired. The evidence and information pertaining to implementation of curriculum change collected through 
monitoring and evaluation could thus strengthen future review and change process of curriculum, and could contribute to the improvement of teaching and learning practices and overall support system.

\section{DISCUSSION}

A range of findings corresponds well with earlier research however many appear as distinctive. The secondary English teachers largely perceived CC2006 as innovative, however expressed that they felt ignored, uninvolved and uninformed about CC2006. During the implementation process of CC2006, instead autonomous professional teachers they were treated as technicians. Although, about the marginalized teachers' involvement our research findings are in line with several earlier studies (Shkedi, 2006; Shawer, 2010; Jenkins, 2014; Reid \& Walker, 2012), but what makes our findings stand out among other findings is the point that not only teachers but astoundingly the heads of schools were also side lined throughout the process of CC2006. Regarding the provision of required resources, English teachers claimed that their schools did not provide resources to teach the English curriculum 2006 and this scenario put them into great pressure. This finding concurs with the results from Wang's (2007) investigation of National curriculum changes and their effects on English language teaching in China through which he found that teachers due to lack of resources available to them felt pressured and fretful about managing change. The findings revealed that the gap between professional preparation of teachers and the demands of CC2006 multiplied the problems of implementation. CC2006 was introduced without taking into account core functionalities such as, school contexts and structure; academic calendar; assessment system (Priestley et al., 2012a). The communication and coordination were centralised, insufficient and ineffective at province, district and school levels. TPD support to secondary English teachers was inadequate to enable them to implement CC2006. This study found that most participants in this study regardless of context shared the belief that success of curriculum change depends upon providing teachers with multiple opportunities for TPD. However, few teacher participants were provided with TPD got any capacity building opportunity since CC2006 was introduced (Cassidy, 2014).

\section{CONCLUSION}

The findings of this research lead to conclusion that curriculum change that is introduced without consulting and engaging teachers in the designing and planning phase is seldom successful. The English CC2006 was launched without providing teachers with appropriate conditions, resources, support and building teachers' capacity to enact change successfully thus, the poorly co-ordinated change gave rise to numerous challenges and problems for the teachers and schools. Based on the findings, it is recommended that teachers' must be involved introducing change in curriculum. Without understanding teachers' ability of and hearing their voices about curriculum change and improving school culture resources and level of support the 'real change' may not happen. In order to support curriculum change, existing policy paradigms also need to be changed. Thus, rather than assuming that practices will change, capacity must be built and teachers' participation in each phase of curriculum change should be enhanced. More the teachers are involved in designing and developing the new practices they are expected to implement, the more favourably they will embrace new ways of teaching (Guskey, 2002; Knight, 2009). It is recommended that the policy makers should take into account the challenges teachers and schools face when implementing changes. Trialling of a new curriculum before its mandatory implementation could also prevent many of the leading challenges that the teachers and schools probably face during implementation.

So far as contribution of this research is concerned, it is significant to mention that this research contributes to the theoretical knowledge in the many ways. The researchers generated theoretical 
framework which adds to the knowledge pertaining to the teachers' perceptions and beliefs about curriculum change and highlights significance of apprehending contextual realities organizational structure, culture, support and resources of schools before launching \& implementing curriculum change. Theoretical framework clearly suggests that for a high-quality curriculum to be embraced and implemented as intended, taking into account teachers, beliefs, perceptions and contextual aspects of a school is crucial. In addition to this, this paper offers two distinct models i.e., the curriculum changes the implementation framework model and the inter-tier collaborative TPD support system model. The former provides a guide to the decisions and actions critical to the successful implementation of curriculum change. The later, on the other hand, introduces a new paradigm of TPD which promotes importance of an active professional support system/culture at provincial, district and school level that offers a wide range of TPD activities to teachers. Overall, findings of this research could greatly influence future practices of curriculum change. It is high time to consider results of this study so that similar patterns of implementation fidelity may be avoided.

\section{REFERENCES}

Ali, T. (2011). Understanding how practices of teacher education in Pakistan compare with the popular theories and narrative of reforms of teacher education in international context. International Journal of Humanities and Social Science, 8(1), 208-222.

Altunoglu, A. (2012). Manifestations of curriculum change on organizational culture. Germany: LAP Lambert Academic Publishing.

Alwan, F.H. (2005). An analysis of English language teachers' perceptions of curriculum changes in the United Arab Emirates. PhD thesis. Exeter [Online]. Available at: http://files.eric.ed.gov / fulltext/ED503767.pdf.

Apple, W. M. (2018). The critical divide: knowledge about the curriculum and concrete problems of curriculum. Policy and Practice, 4:2, 63-66.

Aziz, M., Bloom, E. D., Humair, S., Jimenez, E., Rosenberg, L. \& Sathar, Z. (2014). Education system reform in Pakistan: why, when, and how? Germany: IZA.

Bantwini, D. B. (2009). How teachers perceive the new curriculum reform: Lessons from a school district in the Eastern Cape Province, South Africa. International Journal of Educational Development, 30(1), 83-90.

Barber, M. (2013). The good news from Pakistan. Reform Research Trust, 33.

Barrot, S. J. (2018). English Curriculum Reform in the Philippines: Issues and Challenges from a 21st Century Learning Perspective, Journal of Language, Identity \& Education, DOI: 10.1080/15348458.2018.1528547.

Biesta, G. \& Tedder, M. (2007). Agency and learning in the life course: Towards an ecological perspective. Studies in the Education of Adults, 39(2), 132-149.

Cheng, C. Y. (1994). Effectiveness of curriculum change in school: an organizational perspective. International Journal of Educational Management, 8(3), 26-34.

Cheung, A. C., \& Wong, P. M. (2011). Effects of school heads' and teachers' agreement with the curriculum reform on curriculum development progress and student learning in Hong Kong. International Journal of Educational Management.

Cohen, L., Manion, L., \& Morrison, K. (2007). Research methods in education. New York: Routledge.

Cross, M., Mungadi, R., \& Rouhani, S. (2002). From policy to practice: curriculum reform in South African education. Comparative Education, 38(2), 171-187.

Cuban, L. (ed.) (1992). Curriculum stability and change. USA: American Educational Research Association. Curriculum reforms? 
Darling, H. L. (1998). Policy and Change: Getting beyond Bureaucracy the right to learn. San Francisco: Jossey-Bass.

Dello, B. I. (2009). Curriculum reform and quality education in China: An overview. International Journal of Educational Development, 29, 241-249.

Drew, V., Priestley, M., \& Michael, M. (2016). Curriculum Development Through Critical Collaborative Professional Enquiry. Journal of Professional Capital and Culture, 1(1).

Fernandez, S. T., Ritchie, G. (2003). Analysing pedagogical change: Physics teachers' responses to a new curriculum. Waikato Journal of Education, 9, 91-111.

Flores, A. M. (2005). Teachers views on recent curriculum changes: tensions and challenges. The Curriculum Journal, 16(3), 401-413.

Franke, M. L., Fennema, E., Carpenter, T., Ansell, E., \& Behrend, J. (1998). Understanding teachers' self-sustaining change in the context of professional development. Teaching and Teaching Education, 14(1), 67-80.

Fullan, M. \& Hargreaves, A. (eds.) (1992). Teacher development and educational change London: Falmer.

Fullan, M. (1972). Overview of the innovative process and the user interchange.

Fullan, M.G. (1993). The complexity of the change process, in "In Change forces: probing the depth of educational reform". Falmer Press, pp. 19-41.

Galton, M., MacBeath, J., Page, C., \& Steward, S. (2002). The impact of change on primary teachers' working lives: Report commissioned by the National Union of Teachers concerning the workloads in primary schools. [Online]. Available at: http://www.educ.cam.ac.uk/people/staff/galton/NUTreport.pdf.

Gibson, E. S. \& Brooks, C. (2012). Teachers' perspectives on the effectiveness of a locally planned professional development program for implementing new curriculum. Teacher Development, 16(1), 1-23.

Gleeson, J., Klenowski, V., \& Looney, A. (2020). Curriculum change in Australia and Ireland: a comparative study of recent reforms. Journal of Curriculum Studies, 1-20.

Grossman, M. G., Onkol, E. P., \& Sands, M. (2007). Curriculum reform in Turkish teacher education: Attitudes of teacher educators towards change in an EU candidate nation. International Journal of Education Development, 27, 2, 138-150.

Guskey, T. R. (ed.) (1995). Professional Development in Education: In Search of the Optimal Mix. New York: Teachers College Press.

Harley, K., \& Wedekind, V. (eds.) (2004). Political change, curriculum change and social formation, 1990 to 2002.

Harris, A. (2003). Behind the classroom door: The challenge of organizational and pedagogical change. Journal of Educational Change, 4(4), pp. 369-382.

Hendricks, N.C. (2008) Teachers' perceptions of their ability to implement the National curriculum statement in the GET-Band Nelson Mandela Metropolitan University.

Jamil, R. B. (2009) 'Curriculum reforms in Pakistan. school curriculum policies and practices in South Asian countries', NCERT. New Delhi, India. Available at: http://itacec.org/ document /nepo9 /NCERT\%20Pakistan\%20paper\%20BRJ.pdfS.

Jenkins, Y. G. (2014). A contextual analysis of secondary home economic teachers' agency in a time of mandatory curriculum changes Queensland University of Technology [Online]. Available at: http://eprints.qut.edu.au/76340/1/Gayle_Jenkins_Thesis.pdf (Accessed: 16 September, 2014).

Jones, A. C., \& Anderson, M. (2001). Managing curriculum change. London: Learning and Skills Development Agency.

Kamran, T. (August 23, 2020). The single national curriculum and the problems of education. The News.

Kennedy, C. (1996). Teachers' role in curriculum reform', ELTED, 2(1). 
Kirk, D., \& MacDonald, D. (2001). Teacher voice and ownership of curriculum change. Journal of Curriculum Studies, 33(5), 551-567.

Knight, J. (2009). What can we do about teacher resistance? Professional Learning, 90(7), pp. 508-513 [Online].

Köksal, H. (1995). Reducing teacher resistance to innovations. 6th IFIP World Congress. Aston University, Birmingham UK. Available at: http://linc.mit.edu/linc2013/proceedings/ Session10/Session10Koksal.pdf (Accessed: April 02, 2012).

Majeed, A. (2009). Key reforms for quality improvement in education. [Online]. Available at: http://www.itacec.org/document/nepo9/Annex\%20\%20Key\%20Reforms\%20in\%20edu cation[1].pdf (Accessed: April 22, 2012).

McFarland, C. D. (2008). Linguistic diversity and English in the Philippines. In M. L. S. Bautista \& K. Bolton (Eds), Philippine English: Linguistic literary perspectives (pp. 131-156). Hong Kong, Hong Kong: Hong Kong University Press.

Memon, M. (1989). An illuminative study of curriculum changes in English language teaching and learning in Pakistan. University of Surrey.

Middleton, G., Evans, A. B., Keegan, R., Bishop, D., \& Evans, D. (2014). The importance of parents and teachers as stakeholders in school-based healthy eating programs. In Y. B. Larock, \& D. C. Gustave (Eds.), Health Education: Parental and Educators' Perspectives, Current Practices and Needs Assessment (pp. 233-252). New york: Nova Science Publishers.

Miles, J. (2020). Curriculum reform in a culture of redress: how social and political pressures are shaping social studies curriculum in Canada. Journal of Curriculum Studies, DOI: 10.1080/00220272.2020.1822920

Miles, M., \& Huberman, M. (1994). Qualitative data analysis. an expanded sourcebook 2nd edn. SAGE.

Ministry of Education (2009). The National Education Policy. Islamabad: The Government of Pakistan.

Ministry of Education, Policy and Planning Wing (2009). National Professional Standards for Teachers in Pakistan. Islamabad: Government of Pakistan.

Mutch, C. (2012). The Curriculum change and teacher resistance. [Editorial]. The Curriculum Matters.

Plessis, D., \& Erika, L. (2005). The implementation of outcomes-based education in the Eastern Cape - a management perspective at micro level. University of South Africa [Online]. Available at: http://hdl.handle.net/10500/1529 (Accessed: September 20, 2014).

Pree, D. M. (2012) 'Curriculum development processes', in Curriculum development processes, from knowledge to action. Alberta Education.

Priestley, M. \& Drew, V. (2019). Professional enquiry: An ecological approach to developing teacher agency, in: D. Godfrey \& C. Brown (Eds) An eco-system for research-engaged schools (London, Routledge), 154-169.

Priestley, M. (2011). Schools, teachers, and curriculum change: A balancing act? Journal of Educational Change, 12(1), 1-23.

Rahman, A. N. H. (2014). From curriculum reform to classroom practice: An evaluation of the English primary curriculum in Malaysia. University of York.

Reid, A. W., \& Walker, F. D. (2012). Case studies in curriculum change Great Britain and the United States', in Case Studies in Curriculum Change. Abingdon, Oxon: Routledge, pp. 67.

Shawer, S. F. (2010). Classroom-level curriculum development: EFL teachers as curriculumdevelopers, curriculum makers and curriculum-transmitters. Teaching and Teacher Education, 26, 173-184. 
Sheehan, S. (2013). Investigating global practices in teaching English to young learners. British Council. Available at: http://www.tesolacademic.org/msworddownloads/British \%20Council\%20Res\%20Papers\%20Vol\%201.pdf (Accessed: June 2, 2014).

Shkedi, A. (2006). Curriculum and teachers: an encounter of languages and literatures. Journal of Curriculum Studies, 38(6), 719-735.

Sinnema, C., Nieveen, N. \& Priestley, M. (2020). The Successful futures, successful curriculum:

Smit, B. (2005). Teachers, local knowledge, and policy implementation: A qualitative policypractice inquiry. Education and Urban Society, 37, 292-306.

Spillane, P. J. (1999). External reform initiatives and teachers' efforts to reconstruct their practice: The mediating role of teachers' zones of enactment. Journal of Curriculum Studies 31(2), 143-175.

Tabulawa, R. (1998). Teachers' perspectives on classroom practice in Botswana: Implications for pedagogical change. International Journal of Qualitative Studies in Education 11(2), pp. 249-268.

Utomo, E. (2005). Challenges of curriculum reform in the context of decentralization: The response of teachers to a Competence-Based Curriculum (CBC) and its implementation in schools. Pittsburgh.

Virgilio, J. (1984). The role of the principal in curriculum implementation. Journal of Education, 104(4), 346.

Wallace, S. C., \& Priestley, M. (2011). Teacher beliefs and the mediation of curriculum innovation in Scotland: A socio-cultural perspective on professional development and change. Journal of Curriculum Studies, 43(3), 357-381.

Wang, Q. (2007). The National curriculum changes and their effects on English language teaching in the people's republic of China. 